\title{
Interlabial mass in a neonate with paraurethral cyst
}

\author{
Min-Hua Tseng, Shih-Hua Lin \\ Taipei, China
}

$\Lambda^{3}$ 3-day-old female neonate presented with an interlabial mass after birth. Irritable crying on voiding occurred at the age of 2 days. Physical examination showed a soft, reddish, ovoid cystic mass, approximately $10 \mathrm{~mm}$ in diameter. It was located between the introitus and the anterior wall of distal vagina and obscured the urethral meatus (Fig. 1). Vaginal patency was verified. Sonograpy showed bilateral hydronephrosis. Local aspiration followed by intracystic contrast injection led to the diagnosis of a paraurethral cyst (Fig. 2). After the aspiration, the cyst disappeared and the urethral meatus became visible with the resolution of bilateral hydronephrosis. The neonate remains asymptomatic and the cyst does not recur in a 3-year follow-up.

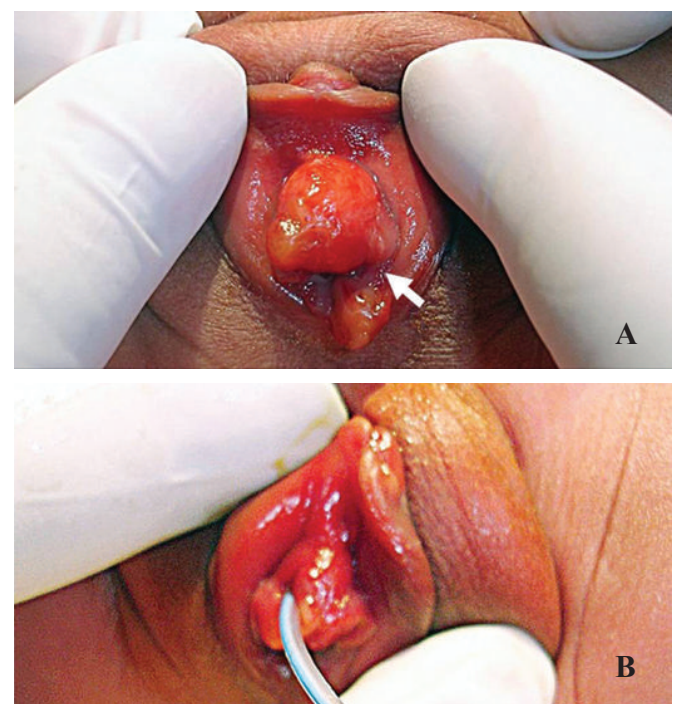

Fig. 1. A: An interlabial mass locates between the introitus and vagina with non-visualized urethral meatus (arrow); B: Paraurethral cyst resolves after aspiration of cyst and distal urethra was catheterized.

Author Affiliations: Division of Nephrology, Department of Pediatrics, Chang Gung Memorial Hospital, and Chang Gung University, Taoyuan, China (Tseng MH, Lin SH); Graduate Institute of Medical Sciences, National Defense Medical Center, Taipei, China (Tseng MH, Lin SH); Department of Medicine, Tri-Service General Hospital, Taipei, China (Lin $\mathrm{SH})$

Corresponding Author: Shih-Hua Lin, MD, Division of Nephrology, Department of Medicine, Tri-Service General Hospital, No. 325 ChengKung Road, Section 2, Neihu 114, Taipei, China (Tel: 886-2- 87927213; Fax: 886-2-87927134; Email: 1521116@gmail.com)

doi: 10.1007/s12519-015-0051-1

Online First November 2015

(C)Children's Hospital, Zhejiang University School of Medicine, China and Springer-Verlag Berlin Heidelberg 2015. All rights reserved.

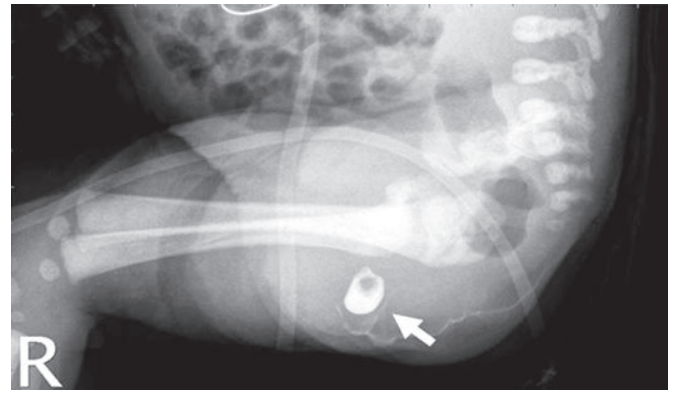

Fig. 2. Intracystic contrast-enhanced radiography showing this cyst has smooth lining without communication with the urinary tract (arrow).

Paraurethral cysts are characterized by the obstruction of the glandular ducts or the cystic degeneration of embryonic remnants of the paraurethral gland and duct. ${ }^{[1]}$ Differential diagnoses are hydrocolpos, botyroid rhabdomyosarcoma of the vagina, prolapsed urethra, ureterocele, urethral diverticulum, and paraurethral cyst. ${ }^{[2]}$ Needle aspiration followed by contrast radiography provides a simple and practical diagnosis and obviates the unnecessary uroradiologic examinations for complicated urethral obstruction. Treatment modalities vary from observation to surgery according to the clinical presentation of cysts. ${ }^{[3,4]}$

Funding: None.

Ethical approval: The consent to report this case has been obtained from the parents of the patient.

Competing interest: None.

Contributors: Tseng $\mathrm{MH}$ interpreted clinical data, and drafted the article. Lin SH provided intellectual input of critical importance to the work and revised the article.

\section{References}

1 Cohen HJ, Klein MD, Laver MB. Cysts of the vagina in the newborn infant. AMA J Dis Child 1957;94;322-324.

2 Badalyan V, Burgula S, Schwartz RH. Congenital paraurethral cysts in two newborn girls: differential diagnosis, management strategies, and spontaneous resolution. J Pediatr Adolesc Gynecol 2012;25:e1-e4.

3 Ceylan H, Ozokutan BH, Karakök M, Buyukbese S. Paraurethral cyst: is conservative management always appropriate? Eur J Pediatr Surg 2002;12:212-214.

4 Phupong V, Aribarg A. Management of Skene's duct cysts in newborn girls. BJU Int 2000;86:562. Accepted after revision May 30, 2014 